\title{
Report on the first Western Pacific and South-east Asian regional conference on sexually transmitted diseases
}

The first Western Pacific and South-east Asian regional conference on sexually transmitted diseases was held at the Regional English Language Centre, International House, Singapore from 6-9 January 1977 . The conference was sponsored by the Dermatological Society of Singapore, the Ministry of Health of Singapore, and the International Union against the Venereal Diseases and the Treponematoses. Dr Benjamin Shears, President of the Republic of Singapore, was the Patron and the Chairman of the Organising Committee was Dr Wong Mook Ow. The Secretary and General Organiser was Dr V. S. Rajan of Singapore.

The conference was attended by more than 200 scientific members from many areas in South-east Asia and the Western Pacific. There was a particularly large contingent from Australia. The World Health Organisation was represented by Dr G. Causse and the International Union against the Venereal Diseases and the Treponematoses by $\mathrm{Dr} R$. D. Catterall.

The opening ceremony was performed on Thursday 6 January by Dr Toh Chin Chye, the Minister of Health of Singapore. He welcomed the delegates to the island and pointed out that the problem of sexually transmitted diseases was particularly important in a city like Singapore which had a large seaport and an even bigger airport.

Dr Wong Mook Ow welcomed members of the conference to Singapore and outlined the programme. Dr R. D. Catterall spoke on behalf of the International Union against the Venereal Diseases and the Treponematoses and welcomed the Foundation of the Western Pacific and South-east Asian Regional Branch of the International Union. Finally, Dr V. S. Rajan gave details of the various sessions and the organisation of the meeting.

Dr Alice Reyn of Copenhagen gave the first guest lecture on the antibiotic susceptibility pattern of Neisseria gonorrhoeae throughout the world. She pointed out that during the past 25 years there had been an increase in resistance of strains of gonococci to penicillin and other antibiotics. This had been most marked in South-east Asia where a high percentage of strains showed decreasing susceptibility to the drug. She also discussed the problem of the new strains of $\beta$-lactamase producing gonococci and measures that could be taken to contain their spread. The rest of the session was devoted to papers from a variety of countries on the problem of gonorrhoea and the sensitivities of gonococci to antibiotics. Various speakers described their experiences with $\beta$-lactamase producing strains of gonococci and Dr V. S. Rajan described three cases that had been seen recently in Singapore, one in a businessman and two in prostitutes. Later in the programme Dr T. Tan described studies of the HLA antigen in patients with sexually transmitted diseases and in another paper described her experience with 500 cases of chancroid and pointed out that 1600 cases had been seen in Singapore in the year 1976. A reliable culture method using inactivated human serum had been found to be the most effective method of diagnosing the condition and Haemophilus ducreyi had been cultured in $35 \%$ of women prostitutes.

On Friday 7 January the second guest lecture was given by Dr R. R. Willcox of St Mary's Hospital, London, entitled Epidemiological Aspects of Sexually Transmitted Diseases-A Worldwide Review. Dr Willcox outlined the scope of the problem of sexually transmitted diseases and discussed the changing social, behavioural, and demographic patterns in modern society. He stressed that the principal difficulty in control was that in most countries many patients were treated by general practitioners and some by pharmacists. No reporting was done and little or no contact tracing carried out. No tests of cure were performed. These difficulties were made worse by the fact that there was no simple method of diagnosing gonorrhoea. Dr Willcox discussed the mathematical possibility of patients contracting a sexually transmitted disease. He pointed out that there had been a fall in the incidence of gonorrhoea in a number of European countries and this had accompanied the economic depression which was at present affecting many areas.

On Friday afternoon several papers were given by representatives from a wide variety of South-east Asian and Western Pacific countries. These papers were called Position Papers and their objective was to outline special problems connected with sexually transmitted diseases in various areas of the world.

Among these was one from Dr Green of Australia 
describing the ituation in Australasia. He pointed out that fewer than $10 \%$ of all cases of sexually transmitted diseases were notified to the state authorities and that the National Committee on Venereal Diseases would shortly be publishing a handbook for practitioners. It was apparent that the situation in Australia was far from satisfactory and that a great deal of work was needed to be done to contain the rising incidence of sexually transmitted diseases. Papers about the situation in Sri Lanka, India, Indonesia, Japan, Malaysia, New Zealand, Nigeria, Papua New Guinea, Singapore, and Thailand were read and provoked considerable discussion.

Later in the afternoon Dr King K. Holmes of Seattle, Washington, USA, presented a paper on $\beta$-lactamase producing gonococci and described the discovery of these organisms in the Philippines and in American servicemen from the Philippines in December 1975 and the further strains that had been found at Liverpool in England, in the USA, and in Singapore. He pointed out that these strains were probably the result of a previously unrecognised plasmid and that it was believed that the $\mathrm{R}$ factor could transfer resistance to other strains. Most strains had minimum inhibitory concentrations of greater than 10 to $200 \mu \mathrm{g} / \mathrm{ml}$ of penicillin and they could best be recognised by testing them with chromogenic cephalosporins when an easily detected colour change would occur in the presence of $\beta$-lactamase producing strains. The recommended treatment of patients infected with such strains was either spectinomycin or kanamycin.

This was followed by a panel discussion chaired by Dr Causse of the World Health Organisation during which a variety of questions were put to a panel of experts by members.

On Saturday morning, 8 January, Dr King K. Holmes gave a paper entitled The Gonococcal Arthritis-Dermatitis Syndrome. Dr Holmes gave a detailed account of a large series of patients with gonococral septicaemia and said that between 60 and $70 \%$ of cases of acute arthritis in young men and women in Seattle were caused by disseminated gonorrhoea. About $69 \%$ of patients presented with arthritis and dermatitis, $23 \%$ with arthritis alone, and $7 \%$ with dermatitis alone. He stressed that the onset of gonococcal septicaemia in women commonly occurs during a menstrual period. Blood cultures are positive only intermittently and therefore several cultures should be taken at different times of the day. The majority of strains causing gonococcal septicaemia were very sensitive to penicillin and so far no $\beta$-lactamase producing strains had been reported in cases of gonococcal arthritis. A few patients with the syndrome had been shown to be deficient in complement production and to have low serum IgM estimations. Treatment with systemic penicillin for three to four days or with ampicillin orally for a total of 10 days was effective.

During the rest of the morning papers were given on various clinical aspects of gonorrhoea, syphilis, and non-specific urethritis.

On Sunday 9 January the guest speaker was Dr R. D. Catterall of the Middlesex Hospital, London, who read a paper entitled Chlamydia Infections and Non-specific Urethritis. The recent literature on Chlamydia trachomatis and its association with non-specific urethritis was reviewed in detail and it was concluded that Chlamydia were probably responsible for about half the cases of non-specific urethritis seen at large clinics; it was also responsible for cervicitis and pelvic inflammatory disease in women, and for eye disease in newborn babies and in some adults. Modern regimens of trea ment were discussed in some detail and the importance of tracing the sexual contacts was stressed. Further research into the remaining cases of non-:pecific genital infection was considered of great importance and the search for a simpler method of detecting Chlamydia was essential if the diagnosis of chlamydial genital infection was to be made outside big centres.

The rest of the morning was devoted to a variety of papers-ranging from false positive serolog cal tests for syphilis seen in Tokyo to the epidemiology of Donovanosis-and including a series of papers describing a medical scheme for the investigation of prostitutes for sexually transmitted diseases in Singapore, the type of sexually transmitted disease found among prostitutes in Singapore, and the epidemiology of these diseases in South-east Asia.

The meeting ended with a special expression of gratitude to Dr V. S. Rajan for the excellent organisation of the meeting and for the smooth way in which the programme had been carried out.

During the conference there were various social events including a buffet reception given by the Government of Singapore at the Istana which was attended by the Minister of Health, Dr Toh Chin Chye. There was a city tour for all delegates on the Saturday afternoon and a banquet at the Jurong Room, Shangrila Hotel on the Sunday evening.

There was universal agreement that the meeting had been a great success and was a great credit to the newly formed South-east Asian and Western Pacific branch of the International Union against the Venereal Diseases and Treponematoses.

R. D. CATTERALL James Pringle House Middlesex Hospital London 